University of Wollongong

Research Online

Faculty of Engineering and Information

Faculty of Engineering and Information

Sciences - Papers: Part A

Sciences

$1-1-2014$

Friction and anti-wear property of aqueous tri-block copolymer solutions in metal forming

Buyung Kosasih

University of Wollongong, buyung@uow.edu.au

Oyong Novareza

University of Wollongong, on934@uowmail.edu.au

A Kiet Tieu

University of Wollongong, ktieu@uow.edu.au

Hongtao Zhu

University of Wollongong, hongtao@uow.edu.au

Follow this and additional works at: https://ro.uow.edu.au/eispapers

Part of the Engineering Commons, and the Science and Technology Studies Commons

Research Online is the open access institutional repository for the University of Wollongong. For further information contact the UOW Library: research-pubs@uow.edu.au 


\title{
Friction and anti-wear property of aqueous tri-block copolymer solutions in metal forming
}

\author{
Abstract \\ Friction and anti-wear property of aqueous symmetrical tri-block normal PEOm-PPOn-PEOm and reverse \\ PPOn-PEOm-PPOn copolymer solutions have been studied. The study focuses on the effect of the \\ solution bulk temperatures and the copolymer block structures. It was found that the concentration and \\ the length of the copolymer blocks affect the solution cloud points, friction and anti-wear property. When \\ solution was supplied at bulk temperature above their cloud point, aqueous copolymer solutions were not \\ able to develop effective adsorbed film resulting in high friction and severe wear. When the bulk \\ temperatures were below the cloud point, the anti-wear property improved significantly and the dynamic \\ friction is lower than that when the temperatures were above the cloud point. This demonstrates the \\ importance of the supply temperature of this type of lubricant in metal forming. However by adding ethyl \\ phosphate ester to the copolymer solutions further improved friction reducing property of the solutions \\ was observed and the friction and anti-wear property of the lubricant become insensitive to bulk \\ temperature. In the effort to understand the lubrication mechanism of the aqueous solutions, wear tracks \\ were studied using scanning electron microscope (SEM) and atomic force microscope (AFM), and the \\ surface wetting ability via contact angle measurements.

\section{Disciplines} \\ Engineering | Science and Technology Studies

\section{Publication Details} \\ Kosasih, B., Novareza, O., Tieu, A. Kiet. \& Zhu, H. (2014). Friction and anti-wear property of aqueous tri- \\ block copolymer solutions in metal forming. International Journal of Surface Science and Engineering, 8 \\ (2/3), 109-123.
}




\title{
Friction and Anti-wear Property of Aqueous Tri-block Copolymer Solutions in Metal Forming
}

\author{
Buyung Kosasih $^{1 *}$, Oyong Novareza ${ }^{1,2}$, Kiet Tieu ${ }^{1}$, and Hongtao Zhu ${ }^{1}$ \\ ${ }^{1}$ School of Mechanical, Materials and Mechatronics Engineering, University of Wollongong, North- \\ fields, \\ Wollongong, NSW 2500, Australia, \\ ${ }^{2}$ Industrial Engineering, Department of Engineering, The University of Brawijaya, Malang, Indonesia
}

Friction and anti-wear property of aqueous symmetrical tri-block normal $P E O_{m}-P P O_{n}-P E O_{m}$ and reverse $P P O_{n}-P E O_{m}-P P O_{n}$ copolymer solutions have been studied. The study focuses on the effect of the solution bulk temperatures and the copolymer block structures. It was found that the concentration and the length of the copolymer blocks affect the solution cloud points, friction and anti-wear property. When solution was supplied at bulk temperature above their cloud point, aqueous copolymer solutions were not able to develop effective adsorbed film resulting in high friction and severe wear. When the bulk temperatures were below the cloud point, the anti-wear property improved significantly and the dynamic friction is lower than that when the temperatures were above the cloud point. This demonstrates the importance of the supply temperature of this type of lubricant in metal forming. However by adding ethyl phosphate ester to the copolymer solutions further improved friction reducing property of the solutions was observed and the friction and anti-wear property of the lubricant become insensitive to bulk temperature. In the effort to understand the lubrication mechanism of the aqueous solutions, wear tracks were studied using Scanning Electron Microscope (SEM), Atomic Force Microscope (AFM) and the surface wetting ability via contact angle measurements, and possible mechanism is discussed.

Keywords: anti-wear, aqueous solutions, cloud point, friction, tri-block copolymer

\section{INTRODUCTION}

Water based lubricants have been used as cold rolling fluids due to their low cost, environmentally friendly nature and non-flammable characteristic. With increasingly stringent quality of the products demanded in rolling applications, lubricants have to meet not only the tribological performance requirement but also the product surface quality and cleanliness [1,2]. Aqueous polymer solutions comprised of symmetrical tri-block copolymers with extreme pressure additives can potentially offer excellent tribological performance and surface cleaning property. Unlike common water based lubricants such as oil-in-water $(O / W)$ emulsions, aqueous surfactant solutions are not subject to bio-instability, phase segregation and disposal problems [3].

Two types of tri-block copolymers were investigated. Normal type comprised of hydrophilic ethylene oxide (EO) blocks and hydrophobic propylene oxide $(P O)$ blocks forming poly(ethylene oxide)poly(propylene oxide)-poly(ethylene oxide) $P E O_{n} P P O_{m} P E O_{n}$ tri-block is one. The other is reverse type comprised of poly(propylene oxide)-poly(ethylene oxide)-poly(propylene oxide) $P P O_{m} P E O_{n} P P O_{m}$ with 
propylene oxide end blocks. In aqueous form, copolymers are soluble non-ionic amphiphilic surfactants [1,2,4-9].

For both types, the hydrophobicity of the $P P O$ block provides essential anchor for the polymer molecules to remain adsorbed on the surface and the PEO blocks remain in the solvent phase [10-13]. However the structural difference of the copolymers types is expected to influence their tribological performance, even though both have the same molecular weight and composition [6]. $P E O_{n} P P O_{m} P E O_{n}$ have been reported to adsorb well on hydrophobic surfaces such as polystyrene latex [14], polypropylene and polyethylene [15,16], poly(ethylene terephthalate), nylon, graphite [17], self-assembled hydrophobic surface [18], and hydrophobic elastomer [19] but the adsorption on metallic surfaces have not been studied.

As there are two distinct phases of the solution depending on the bulk temperature, bulk temperature is also expected to influence the lubrication performance of aqueous polymer solution. As temperature increases the solution solubility decreases due to phase separation at well-defined temperature known as cloud point. Below the cloud point, copolymers are completely dissolved in the solution via hydrogen bonds. However when the lubricant bulk temperature is above the cloud point, poly(propylene oxide) is become more hydrophobic and poly(ethylene oxide) blocks is become less hydrophilic $[6,11,20]$. Both copolymers become insoluble due to the hydrogen bond between water and the copolymer chain is weakened and turning the solution into a two-phase solution $[6,11,20]$ characterized by a change of the solution turbidity. The cloud point has also been shown to be dependent on the concentrations of the polymers [6].

The aim of this work is to study the tribological performance of two types of aqueous symmetrical triblock copolymers with emphasis on the effect of the copolymers molecular weight and block structures, and the bulk temperatures of the solutions.

\section{EXPERIMENTAL DETAILS}

\subsection{Aqueous Solutions}

Four symmetrical tri-block copolymers of normal and reverse types were studied. The normal tri-block copolymers is $\mathrm{PEO}_{m}-\mathrm{PPO}_{n}-\mathrm{PEO}_{m}\left[-\left(-\mathrm{CH}_{2}-\mathrm{CH}_{2}-\mathrm{O}\right)_{\mathrm{m}}-\left(-\mathrm{CH}_{2}-\mathrm{CH}\left(\mathrm{CH}_{3}\right)-\mathrm{O}\right)_{\mathrm{n}}-\left(-\mathrm{CH}_{2}-\mathrm{CH}_{2}-\mathrm{O}-\right)_{\mathrm{m}}-\right]$ with hydrophobic middle blocks and hydrophilic end blocks. The normal copolymers used were commercial Synperonic PE/L62 $\left(\mathrm{PEO}_{6}-\mathrm{PPO}_{34}-\mathrm{PEO}_{6}\right)$ with $\mathrm{M}_{\mathrm{L62}}=2500$ and the equivalent L64 copolymer poly[ethylene glycol]-block-[poly propylene glycol]-block-poly[ethylene glycol] $435449\left(\mathrm{PEO}_{13}-\mathrm{PPO}_{30^{-}}\right.$ $\left.\mathrm{PEO}_{13}\right)$ with $M_{L 64}=2900$. The primary difference between the two is the length of the hydrophilic end blocks.

The reverse tri-blocks $\mathrm{PPO}_{n}-\mathrm{PEO}_{m}-\mathrm{PPO}_{n}\left[-\left(-\mathrm{CH}_{2}-\mathrm{CH}\left(\mathrm{CH}_{3}\right)-\mathrm{O}\right)_{\mathrm{n}}-\left(-\mathrm{CH}_{2}-\mathrm{CH}_{2}-\mathrm{O}\right)_{\mathrm{m}}-\left(-\mathrm{CH}_{2}-\mathrm{CH}\left(\mathrm{CH}_{3}\right)-\mathrm{O}-\right.\right.$ )$_{\mathrm{n}}$-] have hydrophobic end blocks and hydrophilic middle block. For this type commercially available copolymer equivalent to 17R4 poly[propylene glycol]-block-poly[ethylene glycol]-blockpoly[propylene glycol] $435481\left(P^{2} O_{14}-P^{2} O_{24}-P P O_{14}\right)$ with $M_{17 R 4}=2650$ was used. The Synperonic $\mathrm{PE} / 25 \mathrm{R} 2\left(\mathrm{PPO}_{21}-\mathrm{PEO}_{14}-\mathrm{PPO}_{21}\right)$ with $M_{25 R 2}=3100$ is copolymer with longer hydrophobic $P P O$ blocks and shorter $P E O$ was also tested to study the effect of the length of hydrophobic blocks. All copolymers 
were tested under as-received condition without further purification. The detail of the copolymers is given in Table 1.

Table 1. The properties of symmetric tri-block copolymers surfactants.

\begin{tabular}{|c|c|c|c|c|c|c|c|}
\hline \multirow{2}{*}{ No. } & \multirow{2}{*}{$\begin{array}{c}\text { Molecular formula } \\
\text { [mol. mass EO:44, PO:58] }\end{array}$} & \multirow{2}{*}{$\begin{array}{c}\text { Mol. } \\
\text { Weight }\end{array}$} & \multirow{2}{*}{$\begin{array}{c}P P O \\
\text { mol. mass }\end{array}$} & \multirow{2}{*}{$\begin{array}{l}\text { PEO } \\
\% \text { wt }\end{array}$} & \multirow{2}{*}{ HLB } & \multicolumn{2}{|c|}{ Cloud Point $\left[{ }^{\circ} \mathrm{C}\right]$} \\
\hline & & & & & & $1 \%$ & $10 \%$ \\
\hline 1 & $P P O_{14}-P E O_{24}-P P O_{14}$ & 2650 & 1700 & 40 & 12 & 46 & 31 \\
\hline 2 & $P P O_{21}-P E O_{14}-P P O_{21}$ & 3100 & 2500 & 20 & 4 & 29 & insoluble \\
\hline 3 & $\mathrm{PEO}_{6}-\mathrm{PPO}_{34}-\mathrm{PEO} \mathrm{O}_{6}$ & 2500 & 1800 & 20 & 7 & 32 & 24 \\
\hline 4 & $P E O_{13}-P P O_{30}-P E O_{13}$ & 2900 & 1800 & 40 & 15 & 58 & 60 \\
\hline
\end{tabular}

It can be seen in Table 1 that the molecular weight of all tri-block copolymers is not much different. However, the number of hydrophilic blocks affects the cloud points. Tri-block copolymers with $40 \% \mathrm{w}$ of polyethylene oxide appear to have higher cloud point. These copolymers are more hydrophilic [21] and do not normally turn into two phase solutions at above cloud point.

A Millipore water treatment was used to prepare the aqueous copolymer solutions. The solutions with copolymers concentration of $0.06 \mathrm{~g} / \mathrm{ml}$ were prepared 24 hours before each test to ensure equilibrium state was reached. The aqueous copolymer surfactants were also compared with aqueous solutions with Phospholan PE65 containing Ethyl Phosphate Ester of $0.005 \mathrm{~g} / \mathrm{ml}$. PE65 is designed to reduce wear of parts when high pressure is applied.

The measured cloud points were compared with the data from the manufacturers and presented in Table 2. The manufacturers only provide data for $0.01 \mathrm{~g} / \mathrm{ml}$ and $0.10 \mathrm{~g} / \mathrm{ml}$ copolymers concentrations. There is a slight difference between the measured and manufacturers cloud points, e.g. the measured temperature for $P E O_{13}-P P O_{30}-P E O_{13}$ at $0.10 \mathrm{~g} / \mathrm{ml}$ was $1^{\circ} \mathrm{C}$ higher than manufacturer's values.

The cloud point of $P E O_{13}-P P O_{30}-P E O_{13}$ is not changed when $P E 65$ is added. Sharma and Bahadur [21] reported low concentration $P E O_{13}-P P O_{30}-P E O_{13}$ additive such as non-ionic surfactant will not change the cloud point. However, the addition of PE65 to the other aqueous solutions appeared to slightly lower cloud point.

Table 2. Cloud point $\left({ }^{\circ} \mathrm{C}\right)$ of the aqueous copolymer lubricants.

\begin{tabular}{|c|c|c|c|c|}
\hline Conc. & $\begin{array}{c}\mathrm{PPO}_{14-} \mathrm{PEO}_{24^{-}} \\
\mathrm{PPO}_{14}\end{array}$ & $\begin{array}{c}\mathrm{PPO}_{21}-\mathrm{PEO}_{14^{-}} \\
\mathrm{PPO}_{21}\end{array}$ & $\begin{array}{c}\mathrm{PEO}_{6}-\mathrm{PPO}_{34^{-}} \\
\mathrm{PEO}_{6}\end{array}$ & $\begin{array}{c}P E O_{13}-P P O_{30^{-}} \\
P E O_{13}\end{array}$ \\
\hline $6 \%$ & 33 & 29 & 31 & 58 \\
\hline $\begin{array}{c}+ \text { PE65 } \\
0.5 \%\end{array}$ & 32 & 28 & 30 & 58 \\
\hline
\end{tabular}

\subsection{Tribo-pairs}


All ball-on-disk tests were carried out in UMT-2 Multi-Specimen Test System in accordance to ASTM G99-95a [22]. Dynamic friction coefficient $(\mathrm{CoF})$ and ball normal displacement were simultaneously measured. The ball displacement was used to monitor the composite wear of both the ball and the disk. However since the continuous wear depth data obtained from the displacement sensor is not recommended by the standard, the monitored data from the sensor was only used for monitoring the depth change during the test. The values of the wear volume losses of the disks were obtained by calculating the mass difference before and after the tests. These values were verified with those from the ball displacement measurement by assuming negligible ball wear of the case-hardened steel ball.

The tribo-pairs used were mild steel MS1020 disks and case-hardened steel balls of $6 \mathrm{~mm}$ diameter. The surface roughness $\left(R_{a}\right)$ of all disks was $0.3 \mu \mathrm{m}$. The initial surface roughness of the disks was measured before each test. Table 3 lists the mechanical property and surface roughness of the samples. The samples preparations were carried out in accordance with ASTM G133-02 [23]. All ball holder and disk container were cleaned in ultrasonic bath in acetone followed with ethanol for 2 minutes each and dried before tests. After the tests, the disks were ultrasonically cleaned in acetone and ethanol for 2 minutes each and weighed. The values obtained were verified with the measured displacement data from the tester.

To study the adsorption mechanism, steel 15x15 mm square with $5 \mathrm{~mm}$ thick samples from the same batch were prepared. The samples were then polished with 220 grade of silicon carbide followed by 9 $\mu \mathrm{m}$ fine grinding, $3 \mu \mathrm{m}, 1 \mu \mathrm{m}$ cloth and final polishing with $1 \mu \mathrm{m}$ cloth using OP-S liquid. After the processes surface roughness of samples was below $5 \mathrm{~nm}$.

The polished surfaces were cleaned using the same protocol with ball-on-disk test before coating with copolymers. The cleaned sample was fully immersed in lubricant solution at room temperature in one minute, rinsed with Millipore water for 10 seconds and dried spin in a centrifuge at $1000 \mathrm{rpm}$ for $5 \mathrm{~min}$.

Table 3. The properties of the tribo-pairs.

\begin{tabular}{ccccc}
\hline \multirow{2}{*}{ Items } & Hardness & $\begin{array}{c}\text { Young's } \\
\text { modulus } \\
\text { GPa }\end{array}$ & Poisson's ratio & $\begin{array}{c}\text { Surface roughness } \\
\text { Ra } \mu \mathrm{m}\end{array}$ \\
\hline \hline MS1020 & 190 & 206.8 & 0.28 & $0.2 \sim 0.3$ \\
\hline Ball Bearing & $772-832$ & 206.8 & 0.28 & $0.01 \sim 0.02$ \\
\hline
\end{tabular}

\subsection{Test Conditions}

The sliding speed and duration of the tests were maintained at $0.25 \mathrm{~ms}^{-1}$ and 60 min with the total sliding distance of $900 \mathrm{~m}$. The normal load for all tests was maintained at $12.5 \mathrm{~N}$, which produced a maximum and mean Hertzian contact pressure of $1.5 \mathrm{GPa}$ and $1 \mathrm{GPa}$, respectively. The combination of high load and low speed ensured that the tests were carried out under boundary lubrication regime. Each test was done with the disk fully immersed and repeated twice using fresh solutions.

To study the effect of the bulk temperatures, the solutions were prepared at room temperature $\left(25^{\circ} \mathrm{C}\right)$, and $50^{\circ} \mathrm{C}$. Although the lubricants bulk temperature was initially set during the tests, it was seen to increase from $25^{\circ} \mathrm{C}$ at the beginning of the test to about $26^{\circ} \mathrm{C}$ by the time the tests ended. To study the effect of bulk temperature above the cloud point, the solutions were prepared at $50^{\circ} \mathrm{C}$ and $60{ }^{\circ} \mathrm{C}$ for aqueous $P E O_{13}-P P O_{30}-P E O_{13}$ solution as its cloud point is $58^{\circ} \mathrm{C}$ to ensure they were well above the cloud point when the tests started. It would be interesting to do the experiments above the cloud point at a 
higher temperature i.e. $70^{\circ} \mathrm{C}$. However, the cloud point experiment on aqueous $P E O_{13}-P P O_{30}-P E O_{13}$ solution found that it tends to be formed as non-reversible gel at approximately $63^{\circ} \mathrm{C}$. The solution temperatures were recorded during the tests.

\section{RESULTS AND DISCUSSION}

\subsection{Effects of Bulk Temperatures and Block Structures on Dynamic Coefficient of Friction (CoF)}

Figures 1 and 2 present the effect of bulk temperature on the $C o F$ of the reverse $P P O_{n}-P E O_{m}-P P O_{n}$ copolymer types. In Figure 1 the dynamic $C o F$ of aqueous $P P O_{14}-P E O_{24}-P P O_{14}$ used at room temperature $\left(25^{\circ} \mathrm{C}\right)$ increased to 0.30 after about $150 \mathrm{~m}$ of sliding and continued to rise. Below $50 \mathrm{~m}$ the aqueous solution seemed to maintain adsorbed film; the film breakdown appeared after that. At the end of the tests after $900 \mathrm{~m}$ of sliding the $C o F$ is 0.39 . The friction started to plateau after $900 \mathrm{~m}$, signifying formation of stable layer. Similar behavior is seen with the aqueous solution at $50^{\circ} \mathrm{C}$ but the friction increased immediately, signaling breakdown of the film at the start and no formation of adsorbed layer. The dynamic CoF continued to rise reaching 0.49 after $900 \mathrm{~m}$ of sliding. The continuously increasing trend led to seizure and unsustainable vibration at which point the test was discontinued. Different dynamic friction behavior was seen when Phospholan PE65 was added into solution. In this case the friction coefficient was constant at 0.11 irrespective of the solution temperature, which clearly indicates formation of good adsorbed lubricant film in the contact.

The friction behavior of $P P O_{21}-P E O_{14}-P P O_{21}$ solutions is shown in Figure 2 . When used at $25^{\circ} \mathrm{C}$, dynamic friction coefficient continuously rose from the beginning of the test to 0.29 at the end of the test at $900 \mathrm{~m}$. A leveling off of the friction seems to occur at the end of the test. When used at bulk temperature of $50^{\circ} \mathrm{C}$, similar behavior as $P P O_{14}-P E O_{24}-P P O_{14}$ was observed. The friction coefficient rapidly rose to 0.38 at $180 \mathrm{~m}$ and continued to 0.53 at the end of the test $(900 \mathrm{~m})$. Similar to $P P O_{14}-P E O_{24^{-}}$ $P P O_{14}$, continued increasing trend was also observed, which can lead to complete film breakdown and seizure. Adding $P E 65$ into solution has the same effect as in $P P O_{14}-P E O_{24}-P P O_{14}$.

The reverse copolymers having higher number of $P P O$ blocks but shorter $P E O$ blocks in $P P O_{21^{-}}$ $P E O_{14}-P P O_{21}$ show different behavior at $25^{\circ} \mathrm{C}$. In this case the $P P O$ blocks demonstrate a better adsorption on the surface by hydrophobic bonding and seem to separate the surfaces well with shorter hydrophilic blocks. The hydrophilic $P E O$ blocks in $P P O_{14}-P E O_{24}-P P O_{14}$ being longer than the $P P O$ blocks on either side is likely the reason for the higher friction value than $P P O_{21}-P E O_{14}-P P O_{21}$.

Figures 3 and 4 present the dynamic $C o F$ of aqueous reverse $P E O_{6}-P P O_{34}-P E O_{6}$ and $P E O_{13}-P P O_{30^{-}}$ $P E O_{13}$ solutions. Dynamic friction continuously rose and did not reach steady value when used at above the cloud point $\left(50^{\circ} \mathrm{C}\right.$ and $\left.60^{\circ} \mathrm{C}\right)$. The friction is almost double compared to the experiment at $25^{\circ} \mathrm{C}$. The $C o F$ of aqueous $P E O_{13}-P P O_{30}-P E O_{13}$, which has approximately the same numbers of $P P O$ blocks but double the length of $P E O$ blocks, is shown in Figure 4. The increase of hydrophilic end blocks does not seem to result in a different friction behavior to aqueous $P E O_{6}-P P O_{34}-P E O_{6}$. Adding $P E 65$ to the lubricant at $25^{\circ} \mathrm{C}$ and $60^{\circ} \mathrm{C}$ reduces the $\mathrm{CoF}$ to 0.11 similar to aqueous $P E O_{6}-P P O_{34}-P E O_{6}$. In fact it can be said that by adding the Phospholan PE65, the friction reducing characteristic of the solutions was improved irrespective of the temperature and the copolymer structure. The effect is also observed in the reverse polymer cases. 
It can be concluded from the above analysis that the friction coefficient of aqueous copolymer lubricant at above cloud point is much higher than the other. How do aqueous copolymers behave differently at different temperatures? It is assumed that the aqueous copolymer solution turns into two-phase solution when presented with bulk temperatures at above cloud point temperature. Although the $P P O$ become more hydrophobic expected to adsorb better on the surface, however, the $P E O$, which lose the hydrogen bonding with water polymer, become hydrated and pinched out from water [11]. The solution changes into dual-phase state with the copolymers expected turning into the droplets. The PEO chain, which remained extend to the solution at $25^{\circ} \mathrm{C}$ and considered provide phase separation between two contact surfaces [25], is not able to separate the surfaces in droplets formed. The slightly lower friction of the normal copolymers may be explained by the micelle formation of the $P E O_{m}-P P O_{n}-P E O_{m}$ copolymers adsorbing better to the surface and protecting the surface better than $P P O_{n}-P E O_{m}-P P O_{n}$ copolymers at room temperature.

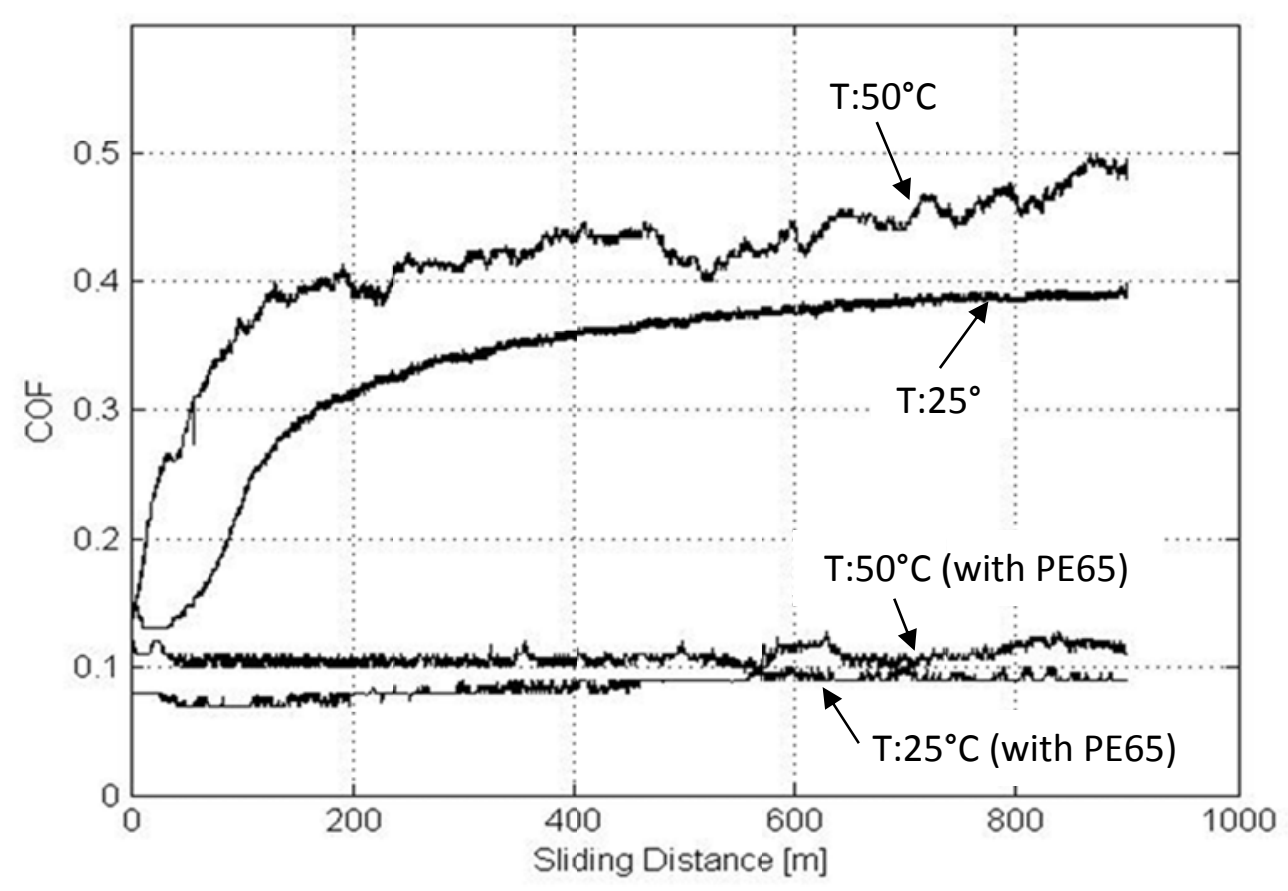

Fig. $1 \mathrm{CoF}$ of aqueous $\mathrm{PPO}_{14}-\mathrm{PEO}_{24}-\mathrm{PPO}_{14}$ at different bulk temperatures. 


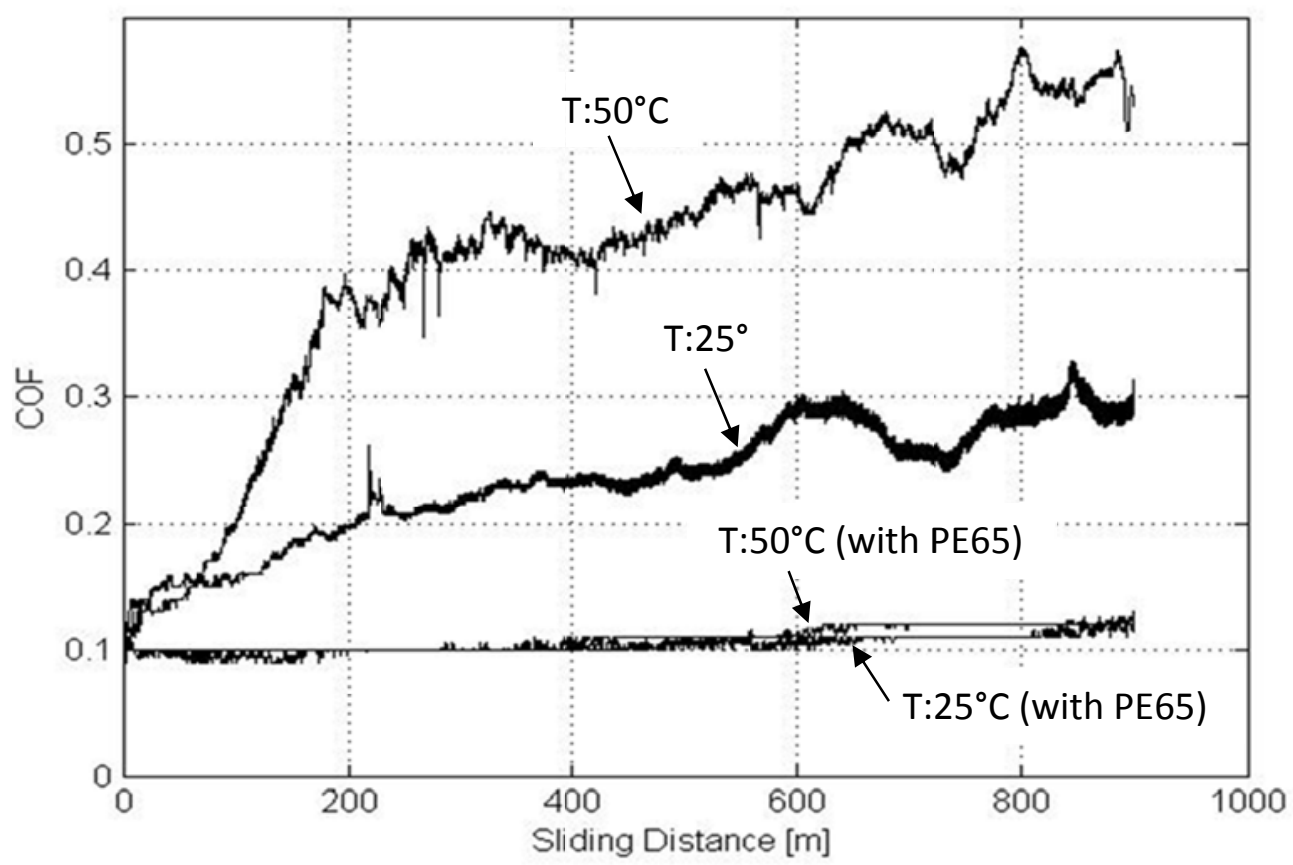

Fig. $2 \mathrm{CoF}$ of aqueous $P P O_{21}-\mathrm{PEO}_{14}-\mathrm{PPO}_{21}$ at different bulk temperatures.

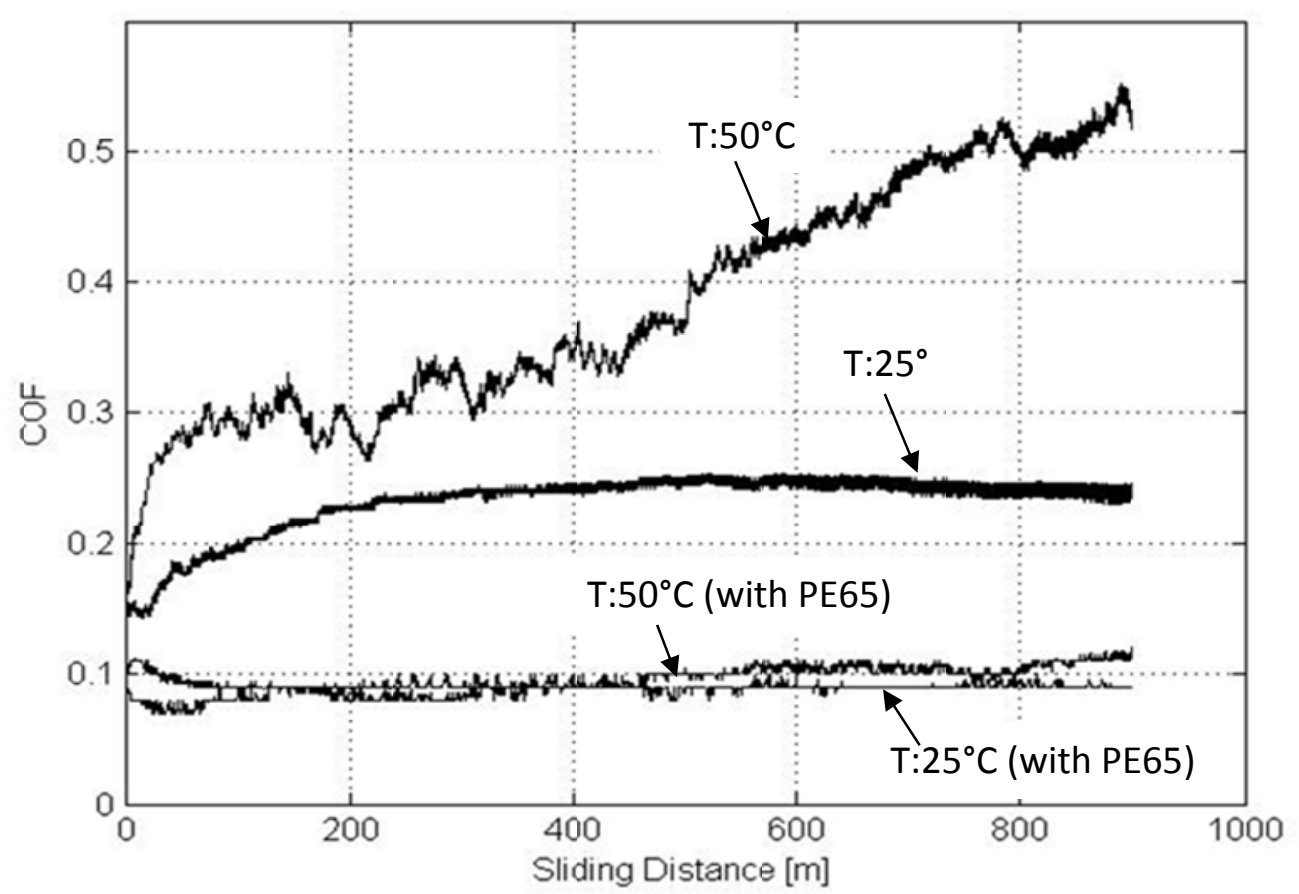

Fig. $3 \mathrm{CoF}$ of aqueous $\mathrm{PEO}_{6}-\mathrm{PPO}_{34}-P E \mathrm{O}_{6}$ at different bulk temperatures. 


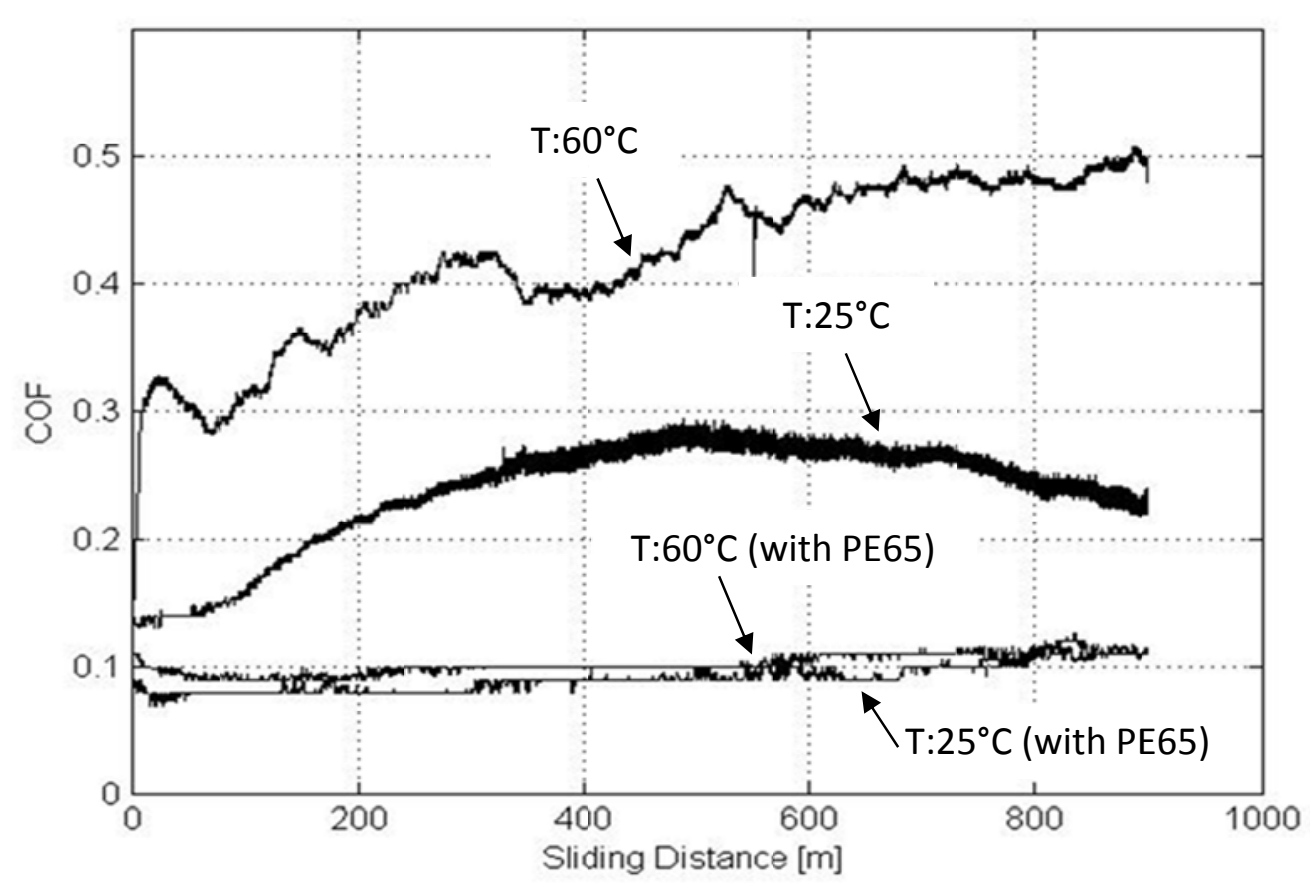

Fig. $4 \mathrm{CoF}$ of aqueous $P E O_{13}-P P O_{30}-P E O_{13}$ at different bulk temperatures.

\subsection{Effects of Bulk Temperatures and Block Structures on material loss (wear)}

The steel disks wear volume is shown in Figure 5. The aqueous $P P O_{14}-P E O_{24}-P P O_{14}$ shows a volume loss of $2.21 \mathrm{~mm}^{3}$ at $50^{\circ} \mathrm{C}$, which is nearly twenty times higher than at $25^{\circ} \mathrm{C}\left(0.12 \mathrm{~mm}^{3}\right)$. The other copolymers with the same structure, $P P O_{21}-P E O_{14}-P P O_{21}$, show similar trend with $0.14 \mathrm{~mm}^{3}$ at $25^{\circ} \mathrm{C}$ and $1.87 \mathrm{~mm}^{3}$ at $50^{\circ} \mathrm{C}$. However, adding PE65 produces lower values in the range of $0.13 \mathrm{~mm}^{3}$ to $0.15 \mathrm{~mm}^{3}$ for $P P O_{14}-P_{24} O_{24}-P_{14}$ and $0.16 \mathrm{~mm}^{3}$ to $0.19 \mathrm{~mm}^{3}$ for $P P O_{21}-P E O_{14}-\mathrm{PPO}_{21}$.

The $P E O_{m}-P P O_{n}-P E O_{m}$ solutions results show similar trend to those with $P P O_{n}-P E O_{m}-P P O_{n}$ solutions. The volume loss is $0.05 \mathrm{~mm}^{3}$ compared to $1.81 \mathrm{~mm}^{3}$ at $50^{\circ} \mathrm{C}$ when lubricated with $P E O_{6}-P P O_{34^{-}}$ $P E O_{6}$. With $P E O_{13}-P P O_{30}-P E O_{13}$ solutions at $60^{\circ} \mathrm{C}$, the wear volume is $1.91 \mathrm{~mm}^{3}$ instead of $0.14 \mathrm{~mm}^{3}$ at room temperature. Wear volume of $0.27 \mathrm{~mm}^{3}$ was measured when PE65 was added. The analysis demonstrates the good anti-wear property of the aqueous solutions when used at temperature below their cloud point.

\subsection{Wear track analysis}

The wear tracks were analyzed using SEM (Jeol JSM-6490LA) and AFM Dual Scope DS 95-200. The AFM was used to measure surface roughness $R_{a}$. Figure 6 shows the SEM images of the wear tracks. There is obvious difference in the wear track surfaces between the aqueous solutions with and without PE65. The tracks appear to have layers of lubricant films when the solutions containing PE65 were used. There are light grooves visible at $50^{\circ} \mathrm{C}$ (Fig. 6 a,b (iv)). The existence of these films explains the low friction of the solutions with PE65 added. Without PE65, wear tracks show groove marks which signify solid-solid plowing contacts. The groove marks appear clearer with the reverse type $\left(P P O_{n^{-}}\right.$ $\left.P E O_{m}-P P O_{n}\right)$. The larger grooves result in rougher surface and larger wear debris. It is clear when the solutions are at above the cloud point $\left(50^{\circ} \mathrm{C}\right.$ and $\left.60^{\circ} \mathrm{C}\right)$; the track is rougher with large groove and possi- 
bly large debris. The flattened debris is visible in Fig. 6(ii). Comparing the two type polymer solutions, the tracks are deeper but narrower for the reverse type compared to those of the normal types $\left(P E \mathrm{O}^{-}\right.$ $\left.P P O_{n}-P E O_{m}\right)$.

The SEM wear track analyses and AFM roughness measurements explain the complete breakdown of the lubricant film when lubricated by solutions at above cloud point. The film breakdown causes severe scratch grooves and large debris. However, when used at bulk temperature below the solution cloud point, aqueous polymer solution has good anti-wear comparable with solution with PE65 anti-wear additive.

\subsection{Contact Angle}

The difference in the friction behavior between the aqueous polymer with and without PE65 is obvious from the CoF results. The difference is thought to be related to alter surface characteristic i.e. hydrophobicity. The more hydrophobic the surface the stronger the bond of the polymer to the surface is expected. To test this hypothesis, contact angle measurements were done.

First, very smooth surface steel disks with surface roughness $R_{a}$ below $5 \mathrm{~nm}$ were prepared. The contact angle on mild steel surface was found to be between $85^{\circ}-87^{\circ}$, which can be considered relatively hydrophobic. Figure 7 shows the result of the water contact angle on the surface covered by the solutions in comparison with the bare surface. It can be seen that contact angle after the application of aqueous solution is lower than the bare surface. This indicates that the PPO block, which is hydrophobic part, has acted as the anchor to the surface and the $P E O$ block, which is hydrophilic left on top. On the contrary, adding $P E 65$ to the solutions increases contact angle value for both $P E O_{m}-P P O_{n}-P E O_{m}$ and $P P O_{n}-P E O_{m}-P P O_{n}$ aqueous solutions and hence transform the top surface layer to be more hydrophobic than bare surface. We speculate that with hydrophobic layer, the copolymer is more readily adsorbed on the surface. However this still leaves the question of how bulk temperature affects the friction of aqueous polymer solution. As we do not have access to test contact angle at temperature above cloud point at this time, this will be confirmed in future study. 


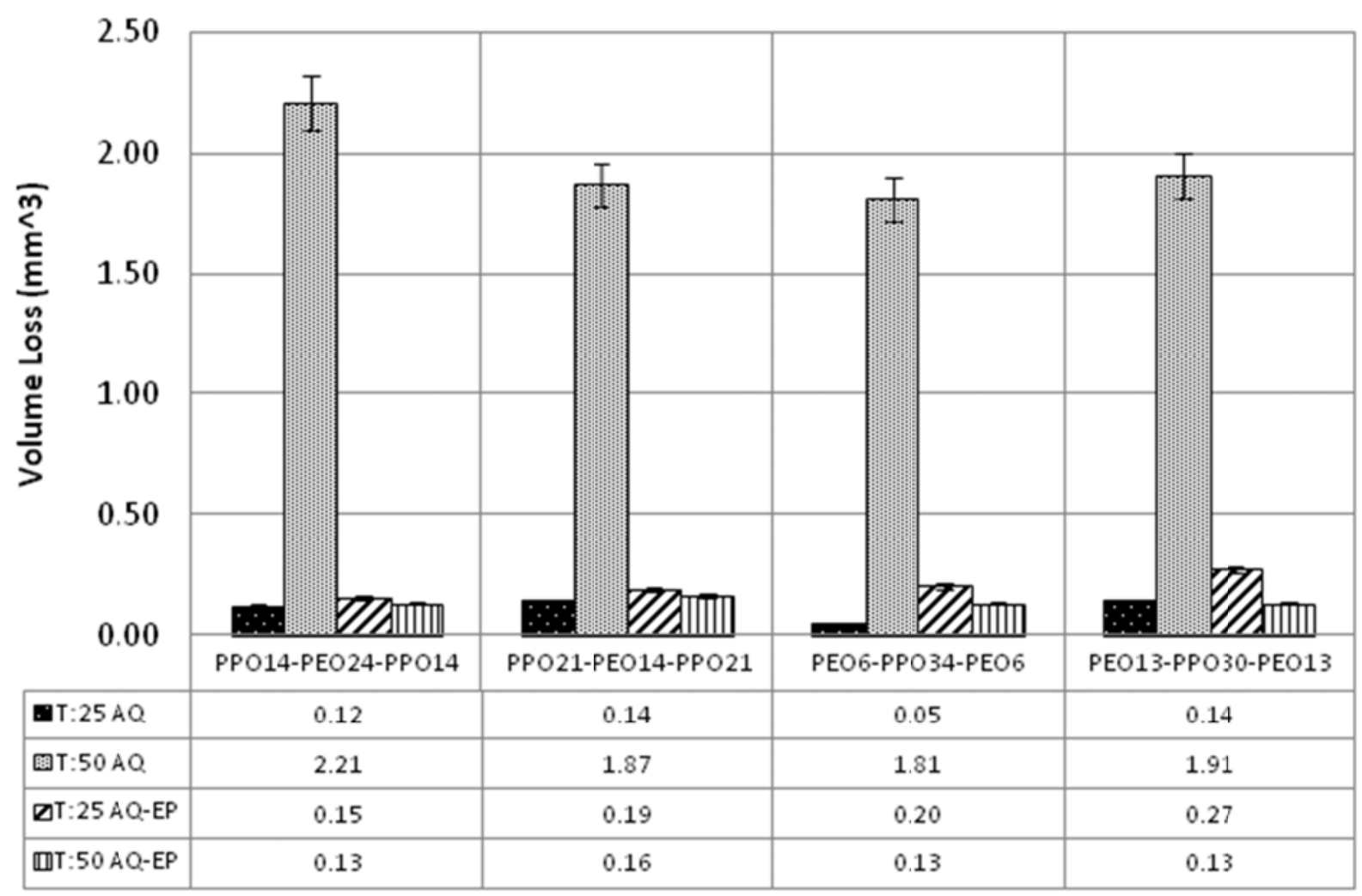

Fig. 5 Summary of wear volume for all tests.

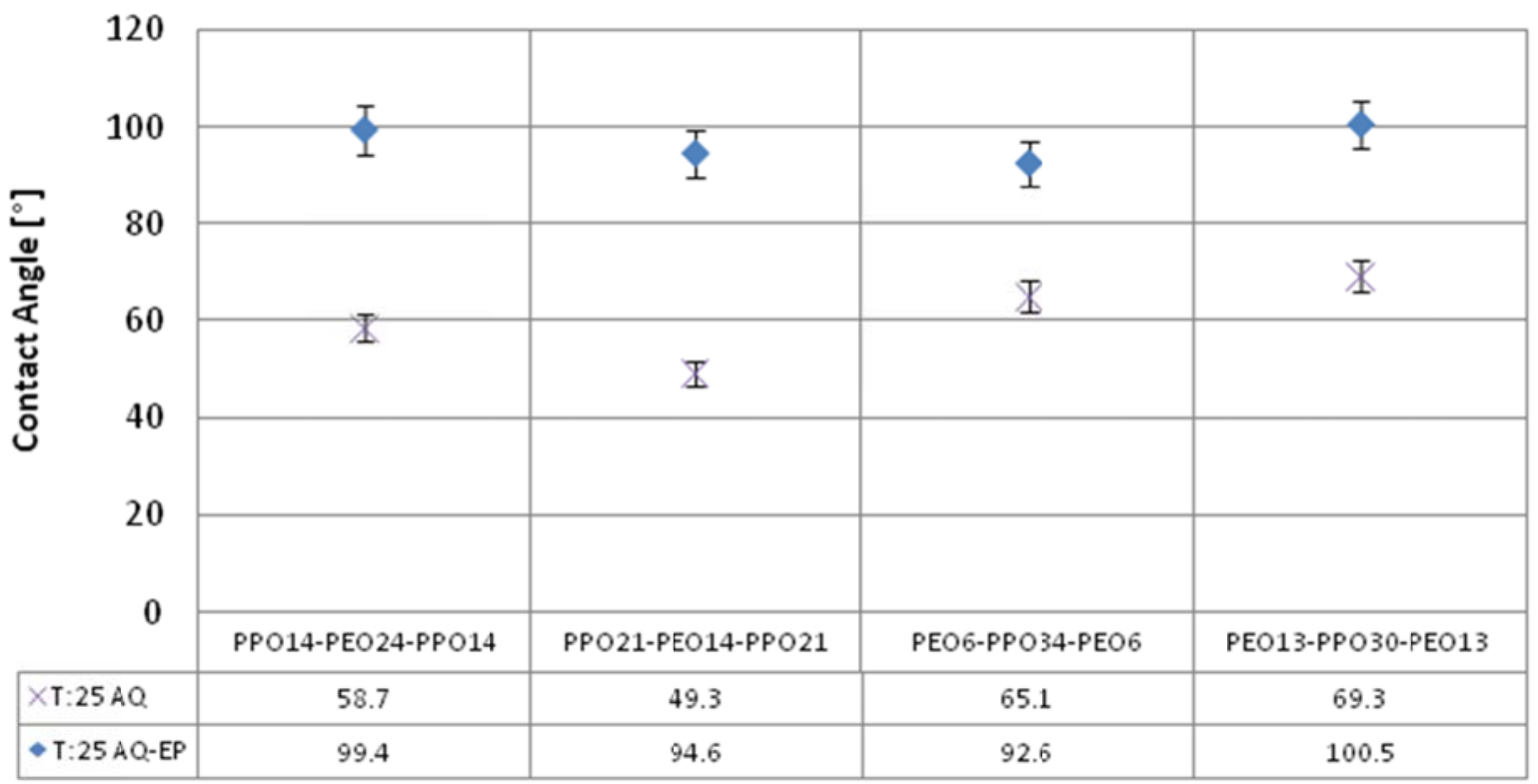

Fig. 7 Water contact angle on mild steel covered by aqueous copolymer lubricants. 


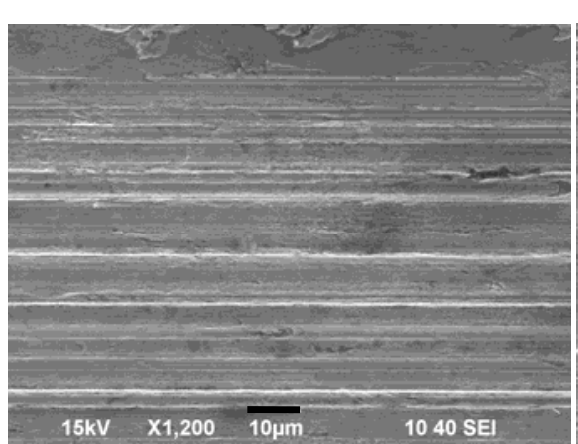

(i) $\mathrm{T}=25^{\circ} \mathrm{C}, \mathrm{R}_{\mathrm{a}}=0.06 \mu \mathrm{m}$

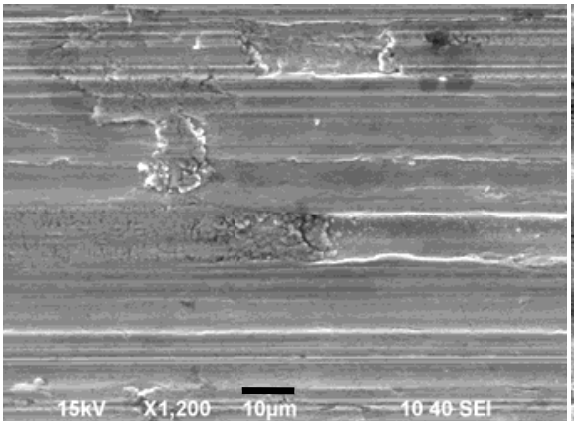

(ii) $\mathrm{T}=50^{\circ} \mathrm{C}, \mathrm{R}_{\mathrm{a}}=0.66 \mu \mathrm{m}$

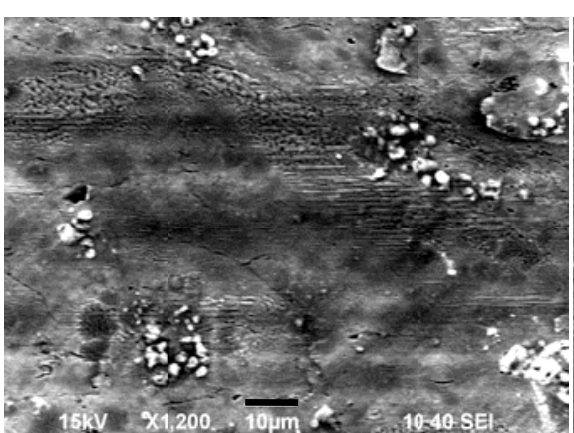

(iii) $\mathrm{T}=25^{\circ} \mathrm{C}, \mathrm{R}_{\mathrm{a}}=0.1 \mu \mathrm{m}[+P E 65]$

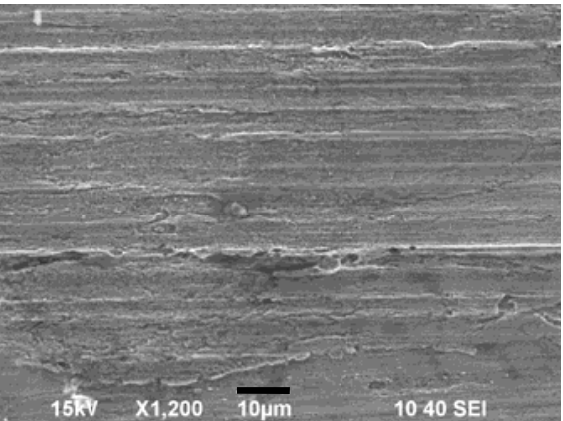

(iv) $\mathrm{T}=50^{\circ} \mathrm{C}, \mathrm{R}_{\mathrm{a}}=0.04 \mu \mathrm{m}[+P E 65]$

(a) $\mathrm{PPO}_{21}-\mathrm{PEO}_{14}-\mathrm{PPO}_{21}$ solutions

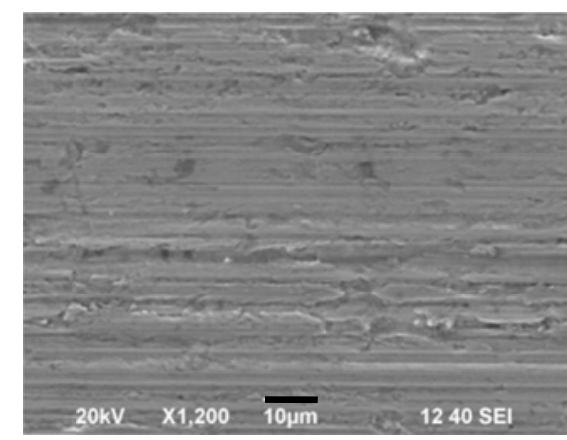

(i) $\mathrm{T}=25^{\circ} \mathrm{C}, \mathrm{R}_{\mathrm{a}}=0.07 \mu \mathrm{m}$

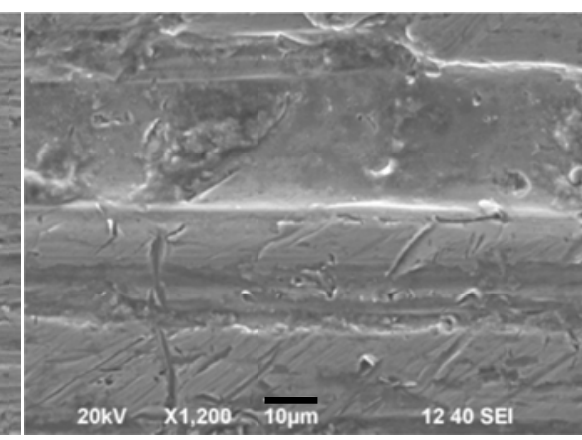

(ii) $\mathrm{T}=50^{\circ} \mathrm{C}, \mathrm{R}_{\mathrm{a}}=0.33 \mu \mathrm{m}$

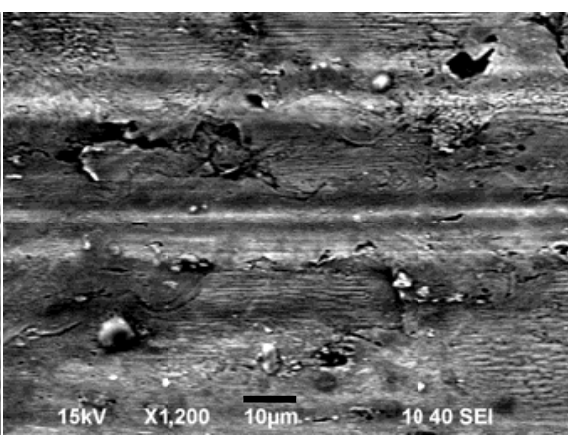

(iii) $\mathrm{T}=25^{\circ} \mathrm{C}, \mathrm{R}_{\mathrm{a}}=0.12 \mu \mathrm{m}[+P E 65]$

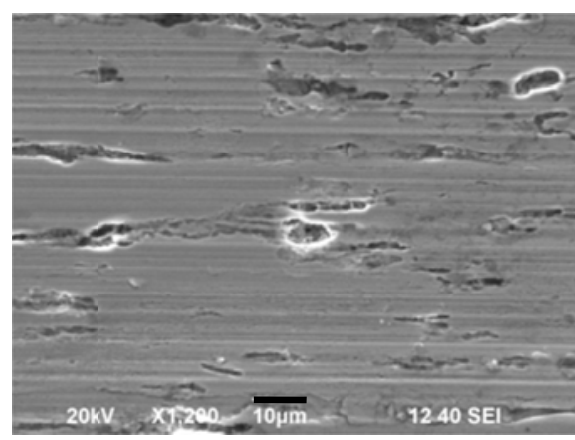

(iv) $\mathrm{T}=50^{\circ} \mathrm{C}, \mathrm{R}_{\mathrm{a}}=0.08 \mu \mathrm{m}[+P E 65]$

(b) $\mathrm{PEO}_{13}-\mathrm{PPO}_{30}-\mathrm{PEO}_{13}$ solutions

Fig. 6 SEM images of the wear tracks lubricated by aqueous solutions. 


\subsection{Lubrication Mechanism of Aqueous Tri-block Copolymers}

In this section we try to explain the lubrication mechanism of the aqueous polymer solutions. Tri-block copolymer solutions are thermally sensitive and behave differently at temperature below and above cloud point. Zhou and Chu [7] studied the phase behavior of $P E O_{m}-P P O_{n}-P E O_{m}\left(P E O_{13}-P P O_{30}-P E O_{13}\right)$

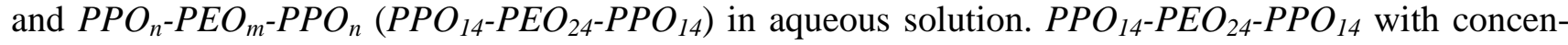
tration of $0.06 \mathrm{~g} / \mathrm{ml}$ has unimer structure at $25^{\circ} \mathrm{C}$ and two-phase structure at $50^{\circ} \mathrm{C}$. Similar phase behavior of $P P O_{21}-P E O_{14}-P P O_{21}$ has been reported by D'Errico et al. [9]. At two-phase state the copolymers are totally separated from the water and exist as droplets in the solution due to the increasing of hydrophobicity of $P P O$ and hydration of $P E O$ create the hydrophilic chain squeezed out from the water [11]. The CoF data shows that in this temperature the value is higher within the range of 0.49 to 0.53 , which means lubricant breakdown occurs at this temperature. The higher volume loss compared to the test at room temperature is consistent with high $\mathrm{CoF}$.

On the other hand, $P E O_{13}-P P O_{30}-P E O_{13}$ is micelle with hydrophobic interior at $25^{\circ} \mathrm{C}$ and transformed into two-phase at $60^{\circ} \mathrm{C}$. In aqueous room temperature environment, $P E O_{m}-P P O_{n}-P E O_{m}$ copolymers adsorb via $P P O$ middle block anchored to the surface and the two $P E O$ end blocks extend out into bulk solution [4,15-18,25]. This may explain the poor adsorption of the normal copolymer at above cloud point. Therefore, although both normal and reverse polymers show similar high friction, the mechanism that leads to the film breakdown is different. It must be noted that the level of hydrophobicity of the surface also plays important role in the adsorption of the copolymers. As copolymer is known to adsorb well on hydrophobic surface $[4,14-19,25]$, the film formation capability of the aqueous copolymers reported here may be different on other metallic surfaces with different level of hydrophobicity.

In general, the $P E O_{m}-P P O_{n}-P E O_{m}$ copolymers show better performance in term of $C o F$ value possibly due to the micelle formation of this copolymer at room temperature. Micelle formation means few numbers of copolymers create one unity that forms like patches on the surface and give better protection to the surface rather than unimer form.

\section{CONCLUSIONS}

Four types of symmetrical tri-block copolymers surfactants used as aqueous solutions have been assessed. The effects of the solutions bulk temperature and the copolymers molecular structures were investigated. It is found that aqueous copolymer solutions can be a good anti-wear lubricant. To reduce friction Phospholan PE65 containing Ethyl Phosphate Ester was added.

The CoFs of aqueous copolymers when used below their cloud points were lower than above the cloud point. It is possible due to the aqueous copolymer lubricant changed into two phase solutions, which both of $P P O$ and $P E O$ are insoluble and formed droplets resulting poor adsorption of lubricant film formation to protect the surface.

In terms of volume loss, mild steel lubricated by aqueous solutions at above cloud point resulted in very high volume loss compared to the volume loss in below cloud point. This can also be related with the existence of the ethyl phosphate ester in aqueous solution which proves to be good friction and wear loss reducer at both bulk temperature setups.

The preliminary study reported in the paper demonstrates the potential of aqueous polymer solutions as environmentally friendly and clean lubricant with good anti-wear property for metal forming applications. 


\section{Acknowledgments}

The authors acknowledge the financial support from Australian Research Council through ARC Discovery grant DP110104823.

\section{References}

1. J.T. Laemmle, Aqueous metalworking lubricant containing polyoxypropylene - polyoxyethylene polyoxypropylene block copolymers, United States Patent 4452711, (1984).

2. J.T. Laemmle, Metalworking with an aqueous synthetic lubricant containing polyoxypropylenepolyoxyethylene-polyoxypropylene block copolymers, United States Patent 4452712, (1984).

3. A. Cambiellaa, J.M. Benitoa, C. Pazosa, J. Cocaa, M. Ratoi, and H.A. Spikes, Tribology Letters 22, 53 (2006).

4. P. Alexandridis and T.A. Hatton, Colloids and Surfaces A 96, 1 (1995).

5. M.A. James-Smith, D. Shekhawat, S. Cheung, B.M. Moudgil, and S.O. Shah, Journal of Surfactants and Detergents 11, 237 (2008).

6. T. Patel, P. Bahadur, and J. Mata, Journal of Colloid and Interface Science 345, 346 (2010).

7. Z. Zhou and B. Chu, Macromolecules 27, 2025 (1994).

8. O. Ortona, G. D’Errico, L. Paduano, V. Vitagliano, Journal of Colloid and Interface Science 301, 63 (2006).

9. G. D'Errico, L. Paduano, and A. Khan, Journal of Colloid and Interface Science 279, 379 (2004).

10. A. Hambardzumyan, V. Agui-Bghin, M. Daoud, and R. Douillard, Langmuir 20, 756 (2004).

11. Q. Wang, L. Li, S. Jiang, Langmuir 21, 9068 (2005).

12. Z. Yang and R. Sharma, Langmuir 17, 6254-6261 (2001).

13. S. Lee and N.D. Spencer, Tribology International 38, 922 (2005).

14. J.A. Baker, J.C. Berg, Langmuir 4, 1055 (1988).

15. Y. Li, H. Liu, J. Song, O.J. Rojas, and J.P. Hinestroza, ACS Appl. Mater. Interfaces 3, 2349 (2011).

16. Y. Li, O.J. Rojas, and J.P. Hinestroza, Ind. Eng. Chem. Res. 51, 2931 (2012).

17. X. Liu, D. Wu, S.T. Cohen, J. Genzer, T.W. Theyson, and O.J. Rojas, Langmuir 26, 9565 (2010).

18. P. Brandani, P. Stroeve, Macromolecules 36, 9492 (2003).

19. S. Lee, R. Iten, M. Muller, and N.D. Spencer, Macromolecules 37, 8349 (2004).

20. G. E. Newby, I.W. Hamleya, S.M. King, C.M. Martin, and N.J. Terrill, Journal of Colloid and Interface Science 329, 54 (2009).

21. R. Sharma and P. Bahadur, Journal of Surfactants and Detergents 5, 263 (2002).

22. ASTM G 99-95a: Standard Test Method for Wear Testing with a Pin-on-Disk Apparatus (2000).

23. ASTM G 133-02: Standard Test Method for Linearly Reciprocating Ball on Flat Sliding Wear (2002).

24. G. Stachowiak and A.W. Batchelor, Engineering Tribology, Third Edition, Elsevier, USA (2005).

25. T.J. Barnes and C. A. Prestidge, Langmuir 16, 4116 (2000).

26. N. Canter N., Special Report: Trends in extreme pressure additives, Tribology \& Lubrication Technology (2007). 